\title{
De la estética de la forma a la estética del significado. Sobre el giro estético de A. Danto*
}

\section{(From the Aesthetics of Form to the Aesthetics of Meaning. On A. Danto's Aesthetic Turn)}

\author{
Matilde CARRASCO BARRANCO
}

Recibido: 10 de septiembre de 2012

Aceptado: 16 de abril de 2013

\section{Resumen}

Con El abuso de la Belleza comenzaría un "giro" en la filosofía del arte de Arthur Danto, marcada por la separación conceptual entre arte y estética, que le ha llevado a reivindicar un importante papel para lo estético en el arte de nuestro tiempo. No obstante, Danto sigue siendo aún reacio a incluir la estética en la definición de lo artístico. El artículo analiza críticamente algunas de sus aportaciones conceptuales más recientes y examina sus implicaciones para esa tesis central de su teoría del arte.

Palabras clave: arte de vanguardia, definición del arte, cualidades estéticas, belleza interna, ideas estéticas.

\begin{abstract}
The Abuse of Beauty can be seen as the beginning of a "turn" in the philosophy of art of Arthur Danto, based on the conceptual divorce between art and aesthetics, through which he has vindicated a significant role for the aesthetic in the art of today. However, Danto is still reluctant to make aesthetics part of the definition of

\footnotetext{
* Este artículo se enmarca en mi trabajo en los proyectos de investigación financiados por el MICINN (FFI2011-23362) y por la Fundación Séneca Agencia de Ciencia y Tecnología de la Región de Murcia (08694/PHCS/08).
} 
art. The paper analyzes some of his most relevant new concepts and examines their implications for that central thesis of his theory of art.

Keywords: artistic avant-garde, definition of art, aesthetic qualities, internal beauty, aesthetic ideas.

\section{Introducción}

Arthur Danto es sin duda una figura sobresaliente en el debate que a mediados del siglo pasado se inició en torno a la definición de lo artístico y que en buena medida ha venido protagonizando la teoría del arte hasta hoy. Es de sobra conocida pues su apuesta por una definición filosófica del arte enmarcada en el divorcio entre arte y estética que acompañaba la producción artística, particularmente la de las artes visuales, más relevante de aquellos años. Así, de todos es conocido también que la filosofía del arte de Danto arranca en buena medida del impacto que causó en él la exposición que Andy Warhol hizo en 1964 de las cajas de madera pintada que simulaban los envases de las esponjas Brillo. Siendo "indiscernibles" desde el punto de vista de su apariencia las cajas de Warhol de las que encontraríamos en los comercios, la estética no parecía tener nada que ver con aquello que convertía a las primeras en arte. Pero sucedía igual con la mayoría de las propuestas artísticas de aquel momento donde la apariencia de las obras no era el principal asunto sino que el énfasis se había trasladado al significado y a las complejas relaciones entre el concepto artístico, el objeto de arte y el medio y el contexto de presentación. ${ }^{1}$ Eran los tiempos de la revuelta contra el formalismo, el enfoque crítico prevaleciente hasta entonces, especialmente en la versión modernista defendida por el influyente crítico de arte Clement Greenberg. ${ }^{2}$ Según éste, una obra de arte presenta de modo accesible en todo momento al ojo crítico todo lo pertinente para su apreciación como arte. Contra esto, Danto se sumó a la corriente "anti-estética" y "externalista" con la tesis de que no eran las cualidades estéticas las que distinguían las obras de arte de otros objetos comunes, dado que la obra de arte no era el objeto físico sino

\footnotetext{
1 Véase Harrison y Wood (1999).

2 Greenberg conectó su concepción de la estética a su teoría modernista del arte, ambas inspiradas en Kant. Por una parte, aplicó la definición kantiana del juicio estético puro a las obras de arte, enfatizando así la dimensión formal, no-cognitiva, de la experiencia estética de las mismas. Por otra parte, si lo que define la modernidad en Kant es la autocrítica, defendió una teoría del valor artístico de acuerdo con la cual el mejor arte moderno era el fruto de una reducción gradual a la esencia de cada arte a través de una investigación reflexiva de los límites específicos de cada medio. La obra de arte moderna, autónoma, quedaba así destinada a producir mediante esa investigación una experiencia estética placentera, desinteresada y reflexiva. Probablemente el escrito de referencia para estas cuestiones es Greenberg (1993).
} 
que aquello que lo convertiría en obra de arte era efectivamente algo externo a él. Convencido tanto de que una definición del arte era más imprescindible que nunca como de que las anteriores definiciones no servían en una situación de pluralismo como la dibujada por el arte de los sesenta, su gran obra, La transfiguración del lugar común, trataba de demostrar que, para ser arte, el objeto tiene que representar algo, siendo su significado una cosa que no puede sin más distinguir el ojo sino que su interpretación necesita apoyarse en una atmósfera de teoría artística, un mundo del arte. 3

Desde entonces la ontología del arte de Danto se mantuvo de forma estable en la separación conceptual entre el arte y lo estético hasta que en 2003 publica $E l$ abuso de la belleza. ${ }^{4}$ Esta obra supondría un punto de inflexión en el pensamiento de Danto puesto que plantea una reconsideración del carácter de lo estético (que le aleja de su comprensión en términos formalistas) y de la relación de la estética con el concepto de arte. En particular, Danto realiza allí una reflexión sobre qué papel pueden jugar en el arte actual la belleza y otras propiedades estéticas, e introduce el concepto de "belleza interna" para referirse a aquélla que contribuye a constituir el significado de la obra de arte. Este concepto puede además extenderse al vasto dominio de las propiedades estéticas distintas a la propia belleza, de manera que supone reconocer el papel que legítimamente pueden jugar éstas en la interpretación y la crítica artística. Visto con perspectiva, El abuso de la belleza supone-como lo expresa el propio Danto tiempo más tarde- el inicio de un "esfuerzo por romper con la estética de la forma a lo Kant-Greenberg y en su lugar desarrollar una estética del significado". 5 Tanto a través de las tesis más relevantes de ese libro como de lo manifestado al respecto en textos posteriores en los que habría madurado su nuevo enfoque, este artículo pretende aproximarse críticamente a ese proyecto en el que Danto se habría embarcado con un "giro" hacia la estética. 6 Mi propósito es examinar las implicaciones de algunas de estas ideas más recientes de Danto para la tesis central de su teoría del arte marcada por la separación conceptual entre arte y estética. Bajo mi punto de vista, el proyecto formaría parte además de una tendencia que, en las últimas décadas y desde puntos de partida muy diversos, viene haciendo una revisión crítica de la concepción heredada del formalismo que entiende la percepción de lo estético en términos puramente sensoriales y lo liga exclusivamente a la belleza y al placer. Esta manera de entender la dimensión estética de las obras de arte como una función del buen gusto justificó la oposición al modernismo, también como manifestación cultural de un poder social y político determinado. Sobre los fundamentos de que el discurso de la estética era política o éticamente regresi-

\footnotetext{
3 Danto (1981).

4 Danto (2005a).

5 Danto (2007), p. 126.

6 Tomo el término de Costello (2008).
} 
vo se desarrolló pues también el programa "anti-estético" postmoderno que hoy día está siendo contestado. ${ }^{7}$ Los nuevos enfoques de lo estético están apostando entonces por una concepción más rica de su naturaleza que permita además replantear sus relaciones con el arte. Aunque no llegará a completar su giro, pienso que el pensamiento estético del último Danto ofrece elementos fundamentales en esa dirección que permitirían demostrar además la relevancia de lo estético para la comprensión y la valoración del arte más reciente.

\section{El pluralismo artístico y el pluralismo estético}

En El abuso de la belleza, Danto confiesa que su anterior filosofía del arte se explica en buena medida por las circunstancias históricas en las que nació. El arte de aquel momento histórico, el del rechazo del modernismo formalista del que derivaba -dice - planteaba la urgencia de encontrar una definición del arte en la que no tenía cabida la belleza ni otras cualidades estéticas similares. Se trataba entonces de definir el arte con independencia e incluso de espalda a la estética, pero ya es hora de volver a ella "habiendo mejorado nuestra comprensión". 8

Lo que parece el primer paso para entender mejor la naturaleza y el ámbito de lo estético es diferenciar entre la belleza y las incontables otras cualidades estéticas posibles y no identificar de manera estrecha estética y belleza. ${ }^{9} \mathrm{Y}$ es que el caso de la belleza es sin duda especial porque, de entre todas esas cualidades, es la única que se reivindica a sí misma como valor entre los bienes morales supremos, en el mismo plano que la verdad y que la bondad. Tradicionalmente fuente de goce y consuelo, promesa de felicidad, la belleza sufrió el rechazo frontal por parte lo que en su libro Danto llama "la vanguardia intratable", paradigmáticamente representada por el Dadá de Zürich, que decidió suprimir y atacar la belleza como gesto de condena hacia la sociedad que la veneraba y a la que hacía responsable de las atrocidades de la I Guerra Mundial. Esa contestación simbólica convirtió al arte bello en colaboracionista, y la vanguardia en la larga estela de Dadá desde entonces hasta nuestros días ha adquirido la responsabilidad moral y política de realizar un arte "antiéstético". A partir de la creencia generalizada de que la belleza trivializa aquello que la posee, la "kalliphobia" que definió la vanguardia intratable se extiende pues por el arte contemporáneo, y con ella los gestos que sustituyen la belleza y la gratificación sensorial por la fealdad, la obscenidad, el ridículo, el exceso, el disgus-

\footnotetext{
7 Véase Costello y Willsdon (2008).

8 Danto (2005a), p. 102.

$9 \mathrm{Ibid}$. Si bien Danto muestra en otras partes del libro una tendencia residual a equiparar belleza y estética.
} 
to y hasta el asco. ${ }^{10}$ De nuevo, en este proceso el impacto de la estética modernista de Greenberg y de otros profesionales del arte en los Estados Unidos -advierte Danto- jugó un papel especialmente relevante. Para Greenberg, la tarea del artista era eliminar de la pintura todo lo que no se dirigiera al ojo crítico, intentado provocar una experiencia estética en la que éste se deleitara en la contemplación de la pura y desinteresada belleza formal. En este enfoque, la calidad artística equivalía a la calidad estética, retomando lo que antaño la estética clásica llamó "gusto". De hecho con el recurso a la "Analítica del gusto" de la Tercera Crítica de Kant, Greenberg intentó fortalecer su planteamiento en un momento en el que los artistas estaban ya convirtiendo en obsoletos la búsqueda del placer estético y la pureza del medio artístico. ${ }^{11} \mathrm{El}$ postmodernismo anti-estético adoptó una posición contra los valores estéticos similar a la de la vanguardia intratable y puso su fe en el poder transformador del arte a través de una revolución estética. La crítica política a la sociedad burguesa se hizo bajo la guisa de una crítica a los valores estéticos con los que asociaban a esa sociedad. 12

Ahora bien, el rechazo del gusto y la calidad estética en el arte de los sesenta y los setenta no eliminó la estética del arte sino que más bien posibilitó su apertura hacia un pluralismo estético paralelo al pluralismo que desde entonces viene dirigiendo los destinos del arte, aunque lo cierto -apunta Danto- es que esto no ha resultado tan fácil de apreciar. La revolución llevada a cabo por los artistas pop, minimalistas o conceptuales en general respecto a la clase de calidad estética presupuesta por la concepción greenbergiana inspirada en Kant, fue de tal magnitud que la cuestión de la definición del arte pasó a primer plano y la estética dio un gran paso atrás hacia una posición insignificante para la práctica, la crítica y la teoría del arte más puntera de la que se estaría recuperando. Danto ha reconocido que su propio trabajo contribuyó a esta situación que vino a silenciar, por ejemplo, los resultados de las investigaciones que en el ámbito de la filosofía del lenguaje se habían hecho sobre los predicados estéticos en los años cincuenta y que dirigían su atención al vasto dominio de las cualidades estéticas, más allá de la belleza, lo sublime o incluso la fealdad, dejando sitio para lo delicado, lo vibrante, lo soso, o lo sucio. ${ }^{13}$ La época que Danto ha llamado de "el fin del arte", la que abre radicalmente las posibilidades de que cualquier cosa pueda ser arte, se extiende hacia la propia estética haciendo que "cualquier cosa sea posible como estética también". ${ }^{14}$ Muchas de

\footnotetext{
10 Danto (2004). En Danto (2005a) se hace referencia a la tesis de Jean Clair que dice que del gusto se ha pasado al asco como la nueva categoría estética dominante en el arte contemporáneo. Véase Clair (2007).

11 Danto (2007), p. 123.

12 Danto (2004), pp. 26-27.

13 Piensa en trabajos como los de Frank Sibley o particularmente J. L. Austin. Danto (2007), pp. 125127.

14 Danto (2004), p. 27. Véase también Danto (1995).
} 
las cualidades estéticas del arte de nuestro tiempo se alejan o incluso son opuestas al estrecho gusto que Greenberg trataba de construir: es el caso de la estética de lo cutre y desordenado ejemplificada por la Cama de Rauschenberg, o la insípida estética de los ready-mades duchampianos, quizá no muy "fácil de describir pero lo bastante fácil de reconocer". 15

En definitiva, para Danto el gran legado de la vanguardia intratable que continúa hoy en una "cultura artística oficial....dadá hasta la médula"16, viene a ser el de haber abierto una brecha lógica irrevocable entre el arte y la belleza, de manera que el arte ya no tiene que ser bello. En aras de un arte social, política y moralmente comprometido se ha desvestido a la belleza de su autoridad moral e incluso se la persigue como algo moralmente reprobable. Pero purgar el concepto de arte de belleza no es lo mismo que purgarlo de cualidades estéticas. La radical apertura del arte de nuestro tiempo exhibe asimismo una gran variedad de modalidades estéticas que demuestran que la estética ha sobrevivido al postmodernismo "antiestético" en la era del pluralismo artístico.

\section{Estética, Retórica y Pragmática}

Ahora bien, la supervivencia de la estética en la época del pluralismo radical no se hace pues en los términos de la estética del gusto abanderada por Greenberg ni en los de la contemplación desinteresada que prescribía al público del arte. Según ese planteamiento, ante una buena obra de arte, bastaría con abrir los ojos y exclamar nuestra admiración antes de que cualquier conocimiento o asociación externa en relación con la obra contaminara nuestra experiencia. En el enfoque formalista greenbergiano, la percepción estética consistiría en la experiencia placentera puramente sensorial con la que responderíamos a los estímulos visuales, y se vaciaría así de cualquier componente cognitivo, o conceptual, como reza la descripción kantiana de la experiencia de la belleza libre. Ahora bien, mientras en la teoría estética formalista de Greenberg u otros como Fry o Bell lo relevante desde un punto de vista estético es el apreciar cómo las cualidades formales de la obra de arte afectan meramente al ojo, para Danto lo es el ver cómo las cualidades estéticas de la obra comprometen al mismo tiempo a la mente. En El abuso..., Danto afirma que las propiedades estéticas en las obras de arte funcionan como "moduladores", en el sentido que sugiere el término fregeano de "color", que "tienen por objeto disponer al público a experimentar sentimientos de una clase u otra respecto a lo que la obra representa". ${ }^{17}$ La belleza puede inspirar amor, la sublimidad terror, la repugnancia asco,

\footnotetext{
15 Danto (2007), p. 126.

16 Danto (2005a), p.101.

17 Ibid., pp. 177, 22-23.
} 
el ridículo desprecio, o la lubricidad sentimientos eróticos y la gama es muy amplia -nos recuerda Danto-; es la función que en otro tiempo se llamó "retórica". 18 Danto define a estas cualidades como "pragmáticas", distintas por tanto de las semánticas, cuyo papel es pues "colorear" el significado de las obras de arte. Entender la función pragmática de las cualidades estéticas exige, por tanto, apreciar su pluralidad, dejar de identificar entonces estética con belleza y placer. Pero también exige diferenciar entre belleza natural y belleza artística "nacida y renacida del Espíritu", como un producto intelectual humano que no se contenta con gratificar a los sentidos. De esta manera, en El abuso..., Danto reivindica como en otros tantos aspectos el pensamiento de Hegel frente al de Kant, quien al juzgar la belleza artística según el modelo de la belleza natural se habría olvidado del significado y de la historia, cuando el arte es -según Danto- significado encarnado.

Ya en La Transfiguración..., Danto argumentaba que las obras de arte, además de ser sobre algo, expresaban un punto de vista hacia ese tema que es el que buscarían transmitir a sus receptores, siendo esto además lo que distingue a las obras de arte de las "meras representaciones". ${ }^{19}$ El cómo expresan ese punto de vista se explicaría entonces siguiendo el modelo de la retórica y sin duda -como ha señalado Danto en otro lugar- esto puede volver peligrosas a las obras de arte. 20 Recordando a Platón, Danto advertía entonces la peligrosidad del arte en los temas que puede tratar y en el efecto retórico que aquí estamos tratando. La retórica - decía- persigue la modificación de la actitud y la creencia, y eso nunca es inocente, y es real, porque las mentes lo son. ${ }^{21} \mathrm{El}$ arte puede ser peligroso pues porque ese poder retórico lo hace efectivo y exige del receptor una atenta mirada crítica que identifique qué propiedades del objeto pertenecen a la obra y como se relacionan con su significado. Pero el hecho de que las propiedades estéticas puedan resultar peligrosas no les restaría relevancia en la construcción del significado de la obra de arte. Sobre esto último, sin embargo, Danto parece también que ha ido cambiando de posición.

Como explica Francisca Pérez Carreño, la noción fregeana de "color", que enfatizaría el componente afectivo de lo estético, es en efecto una noción pragmática

\footnotetext{
18 Ibid, p. 23.

19 Danto (2002), cc. 6 y 7. Danto señala que hay muchos objetos ordinarios (como los mapas o los diagramas) que también son sobre algo, y por tanto tienen contenido semántico, pero esto no es suficiente para convertirlos en obras de arte. Se trataría de una subclase de "las meras cosas reales", que Danto denomina "meras representaciones". Se plantea entonces la necesidad de añadir algo al concepto de representacionalidad para establecer la diferencia entre las representaciones ordinarias y las obras de arte, y ese algo que caracteriza a las obras de arte frente la meras representaciones sería -según Danto- la expresión de una actitud, o un punto de vista hacia su contenido. Véase también Costello (2008), p. 252.
}

20 Danto (2003).

21 Ibid., p. 186. 
que tiene que ver tanto con la producción como con la recepción del signo; es por tanto algo intencionado que pretende causar una experiencia en un intérprete. ${ }^{22} \mathrm{Sin}$ embargo, según Frege, la coloración no cambia el significado del símbolo, ni en cuanto a la referencia, ni en cuanto al sentido, aunque hace manifiesta una preferencia en el uso precisamente de ese signo en lugar de otro. ${ }^{23} \mathrm{Al}$ recurrir a la noción fregeana de coloración, Danto asumiría pues que entender el significado de la obra supone ser capaz de captar ciertos matices que, no obstante, siguen siendo independientes del significado. 24 Jonathan Gilmore ha señalado asimismo que "con el concepto de modulador, Danto quiere diferenciar entre aprehender el contenido intelectual de una obra y estar dispuesto a responder a ese contenido de una cierta forma". 25 Aunque, según objetan estos críticos de Danto, cuando tratamos con obras de arte, eso no parece suceder exactamente así, sino que más bien nos costaría separar ambas cosas. No está claro - continúa, por ejemplo, el argumento de Gilmore- cuánto conocimiento está ya implícito en nuestras respuestas emocionales o en la actitud que adoptamos hacia la obra. Desde una perspectiva pragmática, el propio reconocimiento de los rasgos moduladores de la obra puede que exija por sí mismo cierto aprendizaje o entrenamiento. Como también señala Pérez Carreño, "la coloración no es algo dado, sino una propiedad que el símbolo adquiere en relación a un contexto o una práctica comunicativa, fuera de la cual no existe". ${ }^{26} \mathrm{La}$ función retórica que Danto atribuye pues a las cualidades estéticas presume un grado de coordinación entre el artista y su público que descansa en un conjunto de creencias, en un trasfondo cultural compartido que -añade Gilmore- se hace más evidente aún en el arte contemporáneo. De acuerdo con Gilmore, los moduladores empleados tanto por el "antiéstético" arte contemporáneo (tales como lo abyecto o lo escandaloso) como en el "anestésico" arte del tipo de los readymades de Duchamp, operan cognitivamente de una forma tal que demandan un muy especial conocimiento del tema sobre el que versan. ${ }^{27}$ Con su argumento de "los indiscernibles" el propio Danto ha contribuido a poner de manifiesto que el conocimiento del contex to histórico y artístico de una obra es necesario para apreciación sus cualidades estéticas y, de esta manera, a revisar una concepción de lo estético estrechamente caracterizada en su versión formalista en términos puramente sensoriales y a reconocer su dimensión cognitiva. Pero además, con ello se ha hecho necesaria la reconsideración del papel que juegan las propiedades estéticas en la constitución del significado artístico y por consiguiente de la propia obra sobre la que ahora también reflexiona el propio autor.

\footnotetext{
22 Pérez Carreño (2005), p. 229.

23 Ibid., pp. 223-224.

24 Ibid, p. 229.

25 Gilmore (2005), p. 150.

26 Pérez Carreño (2005), p. 229.

27 Gilmore (2005), p. 151.
} 
La ontología del arte que Danto siempre ha defendido, diferencia claramente en la obra de arte dos componentes, el objeto material y el significado. El objeto tiene un número indeterminado de rasgos físicos de los cuales sólo algunos pertenecerían a la obra. Cuáles sean éstos es asunto, no obstante, de interpretación lo cual nos devuelve al papel esencial que ésta juega en la constitución de la obra de arte, pues la interpretación "es parte de lo que mantiene al significado y al objeto unidos como una obra". 28 De la misma manera, la descripción crítica de la obra que determina qué rasgos del objeto pertenecen a la obra es "integral a su identidad como obra de arte". ${ }^{29}$ Ahora bien, ser capaces de identificar esos rasgos es también ser capaces de saber responder a ellos puesto que, sin el esperado efecto en el espectador, difícilmente se captará el significado de la obra, por lo que la presentación estética de la obra debiera contribuir necesariamente a su dimensión cognitiva y el sentimiento o el afecto estarían vinculados a la naturaleza esencialmente cognitiva del arte.

Claro que, dada la diferencia entre el objeto material y el significado que constituye la obra de arte, es posible que determinados rasgos del primero no pertenezcan a lo segundo, no formen parte de "la estética de la obra". Es tarea de la crítica determinar entonces si la belleza, $u$ otra cualidad estética presente en el objeto, es "interna" o "externa" a la obra. La belleza en el arte es interna cuando su presencia en una obra de arte es parte del significado de la obra, y si no lo es, se considerará una propiedad externa a la misma. Por ejemplo, la famosa Fuente de Duchamp era un urinario de porcelana blanca, de una forma bella e incluso podemos conceder - dice Danto con cierta sorna- que guardaba afinidades con la escultura de Constantin Brancusi. ${ }^{30}$ Pero su belleza es para Danto totalmente externa, puesto que es irrelevante para su significado y para el lugar que ocupa en la historia del arte. Igual dice de sus queridas cajas Brillo de contrachapado con los correspondientes logos con plantilla pintados en sus caras que, a pesar de ser prácticamente indiscernibles de los originales objetos utilitarios, tenían un especial atractivo visual. No podía esperarse menos de un ejemplo de arte comercial, que además era diseño del pintor del expresionismo abstracto James Harvey. De hecho, en El abuso..., Danto afirma que en la estética de la Caja Brillo radicó en buena medida su éxito, frente a otras obras expuestas entonces por Warhol, y en cualquier caso reconoce que desempeñó un importante papel para que él la escogiera precisamente a ella como punto de apoyo para plantear la cuestión que acabaría cimentando su filosofía del arte. ${ }^{31}$ Ahora bien, es distinto cuando la belleza está destinada a jugar un papel en la configuración del significado de la obra. Las Elegías a la República Española de Motherwell o el Memorial a los veteranos de Vietnam de Maya Lin, son ejemplos

\footnotetext{
28 Danto (2005b), p.194.

29 Ibid.

30 Danto (2004), p. 33.

31 Danto (2005a), p. 40.
} 
con los que Danto argumenta que la belleza (artística) puede desempeñar-dice- un papel en el significado de la obra a la que pertenece, uniéndose a él de forma "interna". La belleza de las Elegías es interna al significado de esas pinturas como meditaciones visuales sobre la muerte de un ideal político; la naturaleza sombría de su belleza, la limitada paleta de formas y el uso restringido del color reflejan el luto y buscan modular nuestra actitud de manera que veamos esa pérdida como algo lamentable y nos sintamos afligidos. "El uso de la belleza en las Elegías es hacerle sentir al espectador una emoción adecuada por una forma de vida política caída muchos años atrás, que muchos esperaban que sería bella de haber sobrevivido y prevalecido." 32 Del mismo modo, la belleza del Memorial es interna al intento de curar las heridas abiertas por la guerra en la vida de los americanos. Formado por dos largas alas triangulares unidas en su base, a modo de libro abierto, la orientación horizontal de su forma, la manera cómo uno se aproxima gradualmente a contemplarlo, encaja con un mensaje poco triunfalista desde el punto de vista político; los visitantes se ven reflejados en el granito negro en el que se inscriben los nombres de los fallecidos, uniendo el luto al recuerdo. "Dales belleza, en lugar de cenizas", apuntala su ejemplo Danto con palabras de Isaías, 33 manifestando la analogía del espíritu del diseño de Lin con el que se construirá en la Zona Cero de Nueva York, o de forma más cercana con el de las tumbas que adornamos en los cementerios o el de la música que suena en los funerales. "Es como si la belleza hiciese de catalizador, transformando el dolor crudo en una serena tristeza, ayudando a que las lágrimas salgan y poniendo al mismo tiempo la pérdida, por así decir, en cierta perspectiva filosófica." 34

En estos ejemplos artísticos la belleza no es fortuita ni accesoria sino "constitutiva" e "interpretar estas obras es en parte ofrecer una razón de por qué la belleza era lo que su significado requería". ${ }^{35}$ La distinción entre belleza interna y externa abre entonces una dimensión crítica importante a tener en cuenta cuando se interpreta y evalúa una obra de arte que pasaríamos por alto si consideramos la dimensión estética de la obra en conjunto irrelevante, pero además demuestra que la belleza es una experiencia mucho más rica que la pura emoción óptica o el "estremecimiento retinal" impugnado por Duchamp pues puede formar parte del significado de la obra. 36

Es más, Danto reivindica la opción de la belleza para el arte político o socialmente comprometido. Y eso que Danto es consciente de que la belleza puede ser tratada como algo superficial y falso, y de que puede que haya un conflicto entre belle-

\footnotetext{
32 Ibid., p. 177.

33 Danto (2004), p. 34

34 Danto (2005a), p. 164.

35 Según comenta Gilmore (2005), p. 147.

36 Danto (2005a), p. 147.
} 
za y ciertos contenidos (como el sufrimiento) a los que la belleza no sería la respuesta adecuada (sino la acción o la indignación). La distinción interno/externo nos ayuda también a diferenciar entonces belleza de "embellecimiento" (considerado como equivalente de la falsificación) y a entender que "si la belleza está internamente vinculada al contenido de una obra, una posible crítica a la obra es que sea bella cuando no es adecuado que lo sea". 37

De hecho, los artistas más comprometidos política o socialmente, del presente y del pasado, no habrían despreciado nunca la función pragmática o retórica de las cualidades estéticas de todo tipo que disponen al espectador a adoptar determinadas actitudes frente a determinados contenidos. ${ }^{38}$ Recordemos que la efectividad que prestan a la obra era lo que Danto advertía como posiblemente peligroso. Pero es que además el recurso a la estética no es independiente de la construcción del significado artístico. Por ejemplo, de "rara amalgama entre la excelencia estética y el compromiso ciudadano" ha sido calificada Sunflower Seeds, la instalación de cien millones de pipas de porcelana pintada con la que el artista y activista chino Ai Weiwei alfombró la Tate londinense en 2010 interpretando, a propósito del extraordinario número de pipas que se habían empleado, la idea lo sublime como una de las claves de su complejo significado de especial tinte político. ${ }^{39}$ De modo que el posible peligro retórico de la estética no le quitaría ni su relevancia para el significado de las obras de arte, ni su papel en lo que Danto concluye que es su poder de transformación. Esto es, el "efecto que el arte ejerce en quienes con él se tropiezan". 40 Porque según Danto, los sentimientos que conectan con los pensamientos animan las obras de arte y explican así su importancia para la existencia humana. ${ }^{41}$ $\mathrm{Su}$ devoción por Hegel no le impide a Danto disentir con él por cuanto piensa que el arte no ha sido superado por la filosofía, y mucho menos cuando se ocupa de las grandes cuestiones humanas. Por eso seguiremos necesitando que las ideas se transmitan de forma sensible, probablemente por la manera como estamos hechos. Sea el poder transformador del arte mayor o menor según los casos, se trata pues también de ver el arte desde la perspectiva del papel que juega en nuestras vidas, donde radicaría su verdadera efectividad. La belleza y otras propiedades similares que se volvieron de repente irrelevantes son las que habían jugado un enorme protagonis-

\footnotetext{
37 Danto (2005a), p. 166.

38 Harrison y Wood comentan sobre el comprometido arte postmoderno: aunque "las obras de este tipo actúan claramente con una idea diferente acerca de la tarea del arte aparte de la de la contemplación estética $[\ldots]$ no quiere decir que los recursos compositivos no estén conscientemente desplegados como medios para el fin en cuestión". Harrison y Wood (1999), pp. 242-243.

39 Fernández-Galiano (2010). En este artículo se analizan otros aspectos simbólicos de la estética de esta obra como también el propio artista explica en: http://www.youtube.com/watch?v= PueYywpkJW8

40 Danto (2005a), p. 189.

41 Ibid, pp. 153-154.
} 
mo en el pasado para dar respuesta a la pregunta de para qué sirve el arte. Claro está -como matiza Danto- en el caso de que alguien entonces hubiese formulado una pregunta semejante. Reflexionar hoy sobre ellas está más que justificado, sin embargo, ya que "qué es lo que hace que el arte sea tan significativo para la vida es... ahora, el asunto prioritario". 42

\section{La relación interna de la estética con el significado: las Ideas Estéticas}

La distinción entre belleza interna y externa es, tanto para la mayoría de sus comentaristas como para el propio Danto, la principal contribución filosófica de $E l$ abuso... Los textos posteriores que asimismo estamos comentando muestran que Danto ha continuado puliendo esta idea central cuyas implicaciones algunos han considerado que generan contradicciones con su clásica definición del arte. Así, en La Transfiguración...., Danto establecía dos condiciones para una definición filosófica del arte: que el arte sea sobre algo y por lo tanto que tuviera un significado, y que la obra de arte encarnara ese significado, que es de lo que la crítica de arte se ocuparía. La expresión "significado encarnado" condensaría estas condiciones. 43 Pero el ser sobre algo no era criterio suficiente para hacer de un objeto que represente una obra de arte. Las representaciones ordinarias, o las "meras representaciones" son aquellos objetos que también son sobre algo pero son sólo sobre lo que ellos representan, y no proyectan ningún punto de vista hacia ello, como sí lo hacen las obras de arte. De manera que este criterio distingue a las unas de las otras. Atendiendo a su dimensión pragmática, las cualidades estéticas encarnan a su vez el punto de vista que el artista quiere ofrecer sobre el contenido de las propias obras, por lo que excluirlas de la definición de lo artístico excluiría asimismo esa perspectiva con la que a través de una elipsis retórica, generalmente metafórica, el artista busca comprometer al público en la interpretación de su trabajo. Sin cualidades estético-pragmáticas la obra carecería de un punto de vista que expresar, y del efecto buscado, haciendo indiferente la "mera representación", el ser sobre algo de un objeto cualquiera, de la obra de arte. 44 Sólo por esta razón en aras de hacer coherente su teoría, Danto tendría que admitir que lo estético forma parte de la definición del arte.

Pero no lo ha hecho. En El abuso..., donde "más o menos admitía que la estética era más amplia de lo que tradicionalmente se había reconocido",45 Danto se preguntaba si no habría entonces una tercera condición necesaria para que algo fuese

\footnotetext{
42 Ibid, p. 27.

43 Como lo resume en Danto (2007), p. 125.

44 Esta es la crítica que le dirige Costello (2008), p. 252, y antes n.19.

45 Ibid. el énfasis en la cita es mío. Véase también n. 9.
} 
una obra de arte; la condición que estableciera que una obra de arte "ha de tener alguna cualidad estética", la belleza u otra distinta. 46 Y concluyó este libro mostrando su escepticismo sobre que esto fuera así, de manera que no admitió finalmente esa tercera condición. Decía entonces que albergaba "dudas respecto al papel que desempeñan, si es que lo hacen, las propiedades pragmáticas en el arte actual", o no creía "necesario discutir si hace falta ampliar la definición del arte para hacer de la modulación una condición necesaria". ${ }^{47}$ Como veíamos antes, algunas objeciones se dirigieron entonces a señalar la implicación de la pragmática en la dimensión semántica de la obra en tanto que símbolo o significado encarnado, desde el punto de vista tanto del productor como del receptor de la misma, ${ }^{48}$ y a pesar de seguir calificando de "moduladoras" a las cualidades estéticas, el propio Danto, con su diferenciación entre belleza interna y externa, habría dado cabida a la relevancia de las cualidades estéticas en la constitución del significado de las obras y por consiguiente de las obras mismas, en un sentido que rebasa la externalidad semántica implícita en el uso del término fregeano de "color". Si la belleza es externa a la obra, es insignificante y, si es interna, entonces contribuye a su significado, pero Danto no afirma que necesariamente haya alguna cualidad estética jugando este papel.

Sin embargo, parece difícil que no las haya, incluso hay quien cuestiona que ese papel pueda ser externo. Es lo que señala Gilmore cuando afirma que, al contrario de lo que ocurre en la naturaleza donde nos puede parecer normal apreciar la belleza como algo contingente o puramente casual, sin funcionalidad concreta o propósito alguno, nos resultará extraño considerar la belleza de una obra de arte como algo fortuito o accidental, como un rasgo de la encarnación material de la obra que, sin embargo, no es un rasgo intencionado de la propia obra. ${ }^{49}$ En efecto, una manera de describir la distinción entre belleza interna y externa es advertir que la primera pertenece en exclusiva al dominio del arte, mientras que la segunda es la que paradigmáticamente podemos apreciar en la naturaleza. ${ }^{50}$ Ambos tipos de belleza difieren en su función, ya que la belleza interna está específicamente ligada a un contenido; está cargada de significado. Esto además, de acuerdo con Danto, estaría a la base de lo que Hegel habría intuido cuando declaró, al comienzo de sus lecciones de estética, que la belleza artística era "superior" a la belleza natural. De manera que, si hablar de belleza interna es hablar de belleza artística, igual entonces no sería posible que una obra fuera bella sin que esa belleza fuese interna. O, dicho de otra forma, al contrario entonces de lo implicado por la idea de belleza externa,

\footnotetext{
46 Ibid.

47 Ibid., pp. 27, 177. La cursiva es mía.

48 Recordemos que se trataban de Pérez Carreño (2005) y Gilmore (2005), también Costello (2005).

49 Ibid., p. 149.

50 Gilmore (2005), p. 147.
} 
quizá no sea posible que sólo algunos rasgos del objeto sean rasgos de la obra o, -como lo pone Gilmore- "estén asociados" con ella.51 Aunque él no dirige su denuncia en esta dirección, si Gilmore tiene razón, y la belleza o cualesquiera cualidades estéticas "asociadas" a la obra juegan siempre un papel interno, Danto debería incluirlas en su definición de la obra de arte.

Y sin embargo, la distinción entre la obra y el objeto que señala la ontología del arte de Danto es difícil de eliminar. Por tomar dos ejemplos que el propio Danto da al responder a Gilmore, las grietas que se pudieron apreciar en el Cuadrado Negro de Malevich cuando se expuso en el Museo Guggenheim de Nueva York en 2003 no podían ser interpretadas como internas a su significado y, por tanto, como parte de la obra. Una superficie medio arruinada era inconsistente con el espíritu del Suprematismo, de manera que lo razonable era pensar que el agrietamiento no era interno al significado de la obra sino más bien fruto de factores externos y contingentes que con el paso del tiempo habrían afectado al objeto físico. En definitiva, en este caso las grietas pertenecían al objeto, no a la obra. 52 En cambio, en el caso de la Madonna de la Silla de Rafael, pintada en un panel redondo de roble, mientras el hecho de que sea de roble no parece relevante al significado, la forma circular del panel sí lo sería, y Danto lo relaciona con la creencia de que Rafael retrató a la hija de un posadero con su bebé en la cubierta de un tonel. ${ }^{53}$ De este modo, parece innegable que -como opina Danto- seguimos necesitando de una interpretación que nos ayude en primer lugar a describir los rasgos que en cada caso determinen la obra de arte a la que nos enfrentamos. No obstante, creo que pese a esto Gilmore tendría razón en lo fundamental a la hora de señalar la intuición que tendríamos respecto a considerar relevantes aquellos aspectos estéticos que claramente pertenecen al modo como las obras de arte son presentadas por los artistas, lo cual incluiría algunos de los más famosos casos discutidos por Danto, como los readymades. Danto reconoce que "los readymades no son simples objetos encontrados de producción industrial; son objetos modulados para provocar una actitud de indiferencia estética". ${ }^{54}$ Pero es que también, frente a lo que algunos han dicho por ejemplo de Fuente, aunque el mismo Danto no ve su posible belleza como parte de la descripción de estas obras, y por eso la califica de "externa", afirma que con ellas la "insipidez estética" se constituyó en "una cualidad estética, interna al significado de los readymades". 55 Pero es más -según el mismo Danto corrige a Gilmore- que la obra de arte esté materialmente "encarnada" forma parte de su definición filosófica y no debe ser entendida como la mera conjunción o "asociación" entre el sig-

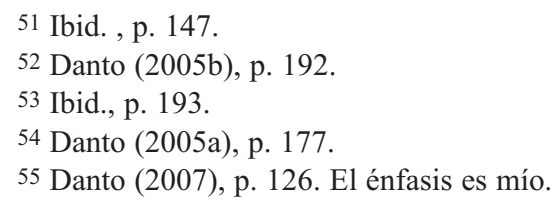


nificado y el objeto, lo cual sería una manera demasiado débil y externa de ver la relación entre ambas cosas. Danto propone en cambio comprenderla de forma análoga a la relación que existe entre el cuerpo y la mente, o el alma, si queremos verlo así; una relación donde los cambios en el cuerpo se relacionan causalmente con sus correspondientes estados mentales o anímicos. Una relación interna, no accidental, de interdependencia, más fuerte pues que lo que el término "asociación", empleado por Gilmore, sugiere. 56 "Significado encarnado" alude por consiguiente al significado de una obra dada y al modo en que ese significado se encarna en el objeto material que la transporta. En cualquiera de sus múltiples e incontables versiones, la dimensión estética, a determinar por la interpretación crítica, se presenta de nuevo entonces como una condición ineludible de las obras de arte como significados encarnados.

Finalmente, el reconocimiento del pluralismo estético y la aplicación al mismo de la distinción entre belleza interna y externa, han hecho que Danto haya reconsiderado incluso la filosofía del arte de Kant que, frente a la hegeliana, veía como elaborada al margen del significado; en particular, la sección 49 de la Crítica del Juicio "De las facultades del Espíritu que constituyen el genio", donde Kant trata el concepto de "ideas estéticas". El Kant de esta sección - dice Danto- no es "el Kant de la estética kantiana, basada casi por completo en la Analítica del Gusto", y su posición allí está muy cerca de la del propio Danto. 57 Porque lo que Kant entendía por presentación de una "idea estética" se parece mucho a lo que Danto entiende por "significado encarnado". 58 Según él mismo lo explica, una idea estética es una idea a la que se le ha dado una encarnación sensorial, con lo que Kant estaría empleando el término "estético" en la línea de Baumgarten, donde generalmente refiere a lo que es dado a los sentidos. En este sentido, enfatiza Danto respecto a Kant, lo que "es maravilloso es que él se ha encontrado con algo que es al mismo tiempo dado a los sentidos $e$ intelectual - donde comprendemos un significado a través de los sentidos, y no ya meramente un color, o un gusto, o un sonido". ${ }^{9}$ El ejemplo de Kant de la representación de Júpiter como un águila que es capaz de agarrar un rayo entre sus garras como la representación de un poder extraordinario presenta esta idea de forma estética, a través de una imagen. Pero nos dice más que la frase "Júpiter es todopoderoso", puesto que la imagen da a la imaginación un impulso para "pensar más" sobre las representaciones, que lo que puede ser expresado en un concepto determinado por palabras. 60

\footnotetext{
56 Danto (2005b), p. 193.

57 Danto (2007), pp. 126-127.

58 Para contrastar también sus diferencias, véase Costello (2008).

59 Danto (2007), p. 127.

60 Concluye Danto citando el § 49 de la Crítica del Juicio. Ibid.
} 


\section{Valor estético y Valor artístico}

Sin duda, el recurso a la estética de Kant sorprende en quien, como Danto tanto la había minusvalorado y opuesto a la de Hegel, pero es que Danto reconoce ahora la naturaleza "espiritual" de las obras de arte en la filosofía del arte de Kant, y la distingue de la analítica del gusto a la que se ciñó la agenda de Greenberg y que lastraría en buena medida aún la recepción actual de la estética kantiana. También puede sorprender asimismo que tras este acercamiento a Kant, y en el reconocimiento del pluralismo estético, Danto siga afirmando que la relación de la estética con el arte sea "siempre externa y contingente" y que, a este respecto, nada ha cambiado. 61

Uno de sus críticos apunta a que la resistencia a modificar su posición en ese aspecto fundamental se debe a que Danto sigue pese a todo preso de una concepción de las propiedades estéticas heredada del formalismo, que las contempla como propiedades perceptivas, en un sentido estrecho, y particularmente como "los rasgos perceptivos de la obra empleados retóricamente para disponer a los espectadores a ver su tema, el significado encarnado en la obra, bajo una cierta luz". ${ }^{62}$ Pero creo que esto choca demasiado con la evolución de Danto que hemos analizado aquí. En especial con las reflexiones de Danto sobre la vinculación conceptual de las cualidades estéticas con el significado de las obras de arte derivadas de la noción de "belleza interna" y aún más de la de "idea estética"(en tanto que "conocimiento sensible"), las cuales manifiestan una concepción más rica de lo estético que supera la estrechez de la visión formalista greenbergiana trasladada asimismo a la ideología postmoderna. ${ }^{63} \mathrm{~A}$ mi juicio, lo que parece preocupar a Danto sería más bien la posibilidad de que la revisión de la noción de lo estético condujera de nuevo a la identificación entre arte y estética, aunque ésta no fuese ya a su vez identificada con la belleza y el placer. Consecuentemente, el valor artístico volvería a identificarse con el valor estético y lo que Danto querría seguir dejando claro es que son dos cosas distintas y que lo primero depende de muchas otras condiciones interpretativas, en particular históricas. El descubrimiento de la "estética del significado" no debería pues hacer peligrar este pilar básico de su filosofía del arte. Quizá por ello, la presencia de cualidades estéticas internas que ha llegado a reconocer en el readymade no es mencionada cuando comenta el atractivo visual de su ejemplo paradigmático, la Caja Brillo, que -insiste en señalar - no tenía nada que ver con lo que la

61 Danto (2007), p. 128.

62 Costello (2008), p. 251.

63 El mismo Diarmuid Costello ha visto así que, mientras que la idea de que podemos distinguir en las obras de arte aquellas cualidades que "colorean" como percibimos el punto de vista expresado por la obra desarrolla lo argumentado en La Transfiguración..., la idea de que estas cualidades constituyen la dimensión estética de la obra que plantea en El abuso... es nueva, y se aleja de la intención de separar conceptualmente el arte y la estética. Costello (2004), p. 426. 
convertiría en obra de arte, con su valor artístico. 64 No obstante, si identificamos valor artístico con valor estético convertiríamos a éste último en condición suficiente del primero, y no sólo necesaria. Ahora bien, lo coherente con la nueva concepción de lo estético que muestra Danto es - pienso - asumir esta necesidad y completar de esta manera su "giro".

Como significado encarnado, la obra de arte no puede prescindir de su dimensión material y estética. Y entender la obra de arte como un significado encarnado, como la presentación de ideas estéticas, implica no sólo que la dimensión material de la obra es ineliminable sino que las cualidades con las que, a diferencia de la naturaleza, los artistas presentan sus obras juegan un papel relevante, interno, constitutivo del significado de las mismas, máxime cuando Danto ha reconocido el vasto dominio de las cualidades estéticas. Pero que la dimensión estética sea ineliminable y necesaria en el pensamiento simbólico que es el arte no quiere decir que ésta agote todas las funciones y valores artísticos, ni que su grado de relevancia crítica no pueda variar en las distintas obras de las que se trate. Lo estético estará siempre presente en las obras de arte como condición necesaria, que no suficiente, y, según los casos, la crítica habrá de determinar si será más o menos determinante para el valor de una obra como arte. De la misma manera, las obras de arte no son los únicos objetos con los que mantenemos una relación estética. Y buena cuenta de ello dan en la literatura filosófica contemporánea el renacimiento de la estética de la naturaleza o la expansión de la reflexión hacia terrenos hasta ahora inexplorados como la experiencia estética de la vida cotidiana. Lo artístico y lo estético coinciden en un punto importante pero no se identifican.

\section{Conclusión}

Desde que la corriente anti-estética y anti-formalista en la práctica, la teoría y la crítica artística desde los 60 marcara el inicio de su filosofía del arte, el pensamiento de Danto en los últimos años ha evolucionado hacia una reconsideración de la naturaleza de lo estético, y de cómo esto podría afectar a su relación con el arte. Desde entonces ha reconocido que, de manera incorrecta, la estética se había identificado "de forma reduccionista con la belleza", y que tras purgar al arte de la belleza "se dedujo, de manera natural, que podíamos aislar el análisis filosófico del arte de toda preocupación, de la clase que fuera, por la estética, y tanto más cuanto que a la estética se la relacionaba tanto con la belleza natural como con la artística". 65 Cuando "que la belleza no forme parte ni de la esencia ni de la definición del arte" no significa que "la estética no forme parte ni de la esencia ni de la definición del

64 Danto (2005a), p. 40.

65 Danto (2005a), pp. 102-103. 
arte". ${ }^{66}$ La separación conceptual entre el arte y la belleza lograda por la vanguardia intratable, y perpetuada por su larga estirpe, no tiene marcha atrás pero tampoco tiene porqué corresponderse con otra brecha igual entre el arte y la estética. Y sin embargo, ni la asunción de la dimensión estética de la obra, ineliminable, una vez que ya sabemos que el arte no tiene que ser necesariamente bello y su apariencia puede ser de lo más variada, ni la aceptación del papel interno al significado que pueden jugar las distintas cualidades estéticas o pragmáticas en las obras de arte, ni el reconocimiento del poder transformador de las mismas y la reivindicación de su empleo para el arte político o comprometido, ni en definitiva la relevancia de la dimensión estética en la interpretación y la evaluación crítica del arte, habrían bastado para completar el giro estético que Danto habría dado a su filosofía del arte desde la publicación de El abuso de la Belleza. Ni siquiera su tardía unión con Kant, a pesar de afirmar que "la teoría del arte como significados encarnados - o de la "presentación de ideas estéticas"- deja claro cómo las cualidades estéticas pueden contribuir al significado de la obra que las posee". 67 Nada de esto le habría hecho admitir que la presencia de cualidades estéticas es un rasgo necesario de todas las obras de arte. Pero las objeciones recogidas aquí argumentan que las implicaciones de sus nuevas ideas apuntan a que, por el contrario, lo más coherente sería más bien revisar finalmente ese punto de partida de su ontología del arte y completar el giro. Aún sin ser suficiente, una vez liberada de la estrecha concepción formalista, la dimensión estética de la obra puede reivindicarse como condición necesaria de lo artístico, y por consiguiente no debería seguir siendo externa a la definición del arte.

La "estética del significado" que Danto ha buscado desarrollar, alejándose de su anterior "estética de la forma", vincula la estética a la dimensión esencialmente cognitiva del arte y es, una vez más con Hegel, hija de su época. Danto reconoce que el panorama ha cambiado. "La estética deambulaba realmente por un territorio yermo hasta que el prejuicio antiestético del arte contemporáneo la puso por el buen camino de nuevo una vez más." 68

\section{Referencias bibliográficas}

Clair, J. (2007): De Inmundo, Madrid, Arena.

Costello, D. (2008): "Kant and Danto, Together at Last?" en K. Stock y K. Thomson-Jones (eds.) New Waves in Aesthetics, Palgrave Macmillan, pp. 244266.

\footnotetext{
66 Ibid.

67 Danto (2007), p. 128.

68 Danto (2007), p. 129, n.1.
} 
Costello, D. (2005): "Intención e interpretación: aporías de la crítica a la Teoría Estética de Danto" en F. Pérez Carreño (ed.) Estética después del fin del arte. Ensayos sobre Arthur Danto, Madrid: Antonio Machado, pp. 233-256.

Costello, D. (2004): “On Late Style: Arthur Danto's The Abuse of Beauty", British Journal of Aesthetics, 44/4, pp. 424-439.

Costello, D. y Willsdom, D. (2008): "Introduction" en D. Costello y D. Willsdom(eds) The Life and Death of Images: Ethics and Aesthetics. Co-edited with Dominic Willsdon, London: Tate Publishing and Cornell UP.

DAnto, A. (2007): "Embodied Meanings, Isotypes, and Aesthetical Ideas", The Journal of Aesthetics and Art Criticism, 65/1, , pp. 121-129.

DAnto, A. (2005a): El abuso de la Belleza, Barcelona, Paidós.

Danto, A. (2005b): "Embodiment, Art History, Theodicy, and The Abuse of Beauty: A Response to My Critics", Inquiry, 48/2, pp. 189-200.

DANTO, A. (2004): "Kalliphobia in Contemporary Art", Art Journal, 63/ 2, pp. 2435.

DAnTo, A. (2003): “Arte peligroso" en Más allá de la caja brillo: las artes visuales desde la perspectiva posthistórica, Madrid, Akal, pp. 173-187.

DAnTo, A. (2002): La transfiguración del lugar común, Barcelona, Paidós.

Danto, A. (1995): After the End of Art: Contemporary art and the Pale of History, Princeton, N. J., Princeton University Press.

Fernández Galiano, L. (2010) "Semillas de Porcelana", Diario EL PAIS, 6 de noviembre de 2010, p. 29.

Greenberg, C. (1993): "Moderninst Painting", en Harrison, C. y Wood, P. (eds) Art in Theory 1900-2000: An Anthology of Changing Ideas, Blackwell, Oxford UK; Cambridge, Massachusetts, pp. 750-760.

Harrison, C. y Wood, P. (1999): "Modernidad y Modernismo", en Wood, P., Frascina, F., y Harris, C. (1999): La modernidad a debate. El arte desde los cuarenta, Madrid, Akal.

Gilmore, J. (2005): “Internal Beauty”, Inquiry, 48/2, pp. 145-154.

Pérez Carreño, F. (2005): "Símbolo encarnado: del cuerpo al efecto", en F. Pérez Carreño (ed.) Estética después del fin del arte. Ensayos sobre Arthur Danto, Madrid: Antonio Machado, pp. 209-232.

WeI WeI, A. (2010): Sunflower Seeds: http://www.youtube.com/watch?v= PueYywpkJW8

Matilde Carrasco Barranco

Departamento de Filosofía

Universidad de Murcia

matildec@um.es 